\title{
BMJ Open Quality Improving management of hospitalised patients with COVID-19: algorithms and tools for implementation and measurement
}

\author{
Ahmed Salem, ${ }^{1,2}$ Hossam Elamir (10 , ${ }^{3}$ Huda Alfoudri, ${ }^{4}$ Mohammed Shamsah, ${ }^{4}$ \\ Shams Abdelraheem, ${ }^{5}$ Ibtissam Abdo, ${ }^{3}$ Mohammad Galal, ${ }^{3}$ Lamiaa Ali ${ }^{3,6}$
}

To cite: Salem A,

Elamir $\mathrm{H}$, Alfoudri $\mathrm{H}$, et al. Improving management of hospitalised patients with COVID-19: algorithms and tools for implementation and measurement. BMJ Open Quality 2020;9:e001130. doi:10.1136/ bmjoq-2020-001130

- Additional material is published online only. To view, please visit the journal online (http://dx.doi.org/10.1136/ bmjoq-2020-001130).

Received 23 July 2020 Revised 12 0ctober 2020 Accepted 8 November 2020

\section{Check for updates}

(c) Author(s) (or their employer(s)) 2020. Re-use permitted under CC BY-NC. No commercial re-use. See rights and permissions. Published by BMJ.

For numbered affiliations see end of article.

\section{Correspondence to} Dr Hossam Elamir; dr_hossam_elamir@hotmail. com

\section{ABSTRACT}

Background The COVID-19 pandemic represents an unprecedented challenge to healthcare systems and nations across the world. Particularly challenging are the lack of agreed-upon management guidelines and variations in practice. Our hospital is a large, secondarycare government hospital in Kuwait, which has increased its capacity by approximately $28 \%$ to manage the care of patients with COVID-19. The surge in capacity has necessitated the redeployment of staff who are not welltrained to manage such conditions. There was a great need to develop a tool to help redeployed staff in decisionmaking for patients with COVID-19, a tool which could also be used for training.

Methods Based on the best available clinical knowledge and best practices, an eight member multidisciplinary group of clinical and quality experts undertook the development of a clinical algorithm-based toolkit to guide training and practice for the management of patients with COVID-19. The team followed Horabin and Lewis' sevenstep approach in developing the algorithms and a five-step method in writing them. Moreover, we applied Rosenfeld et als five points to each algorithm.

Results A set of seven clinical algorithms and one illustrative layout diagram were developed. The algorithms were augmented with documentation forms, data-collection online forms and spreadsheets and an indicators' reference sheet to guide implementation and performance measurement. The final version underwent several revisions and amendments prior to approval. Conclusions A large volume of published literature on the topic of COVID-19 pandemic was translated into a user-friendly, algorithm-based toolkit for the management of patients with COVID-19. This toolkit can be used for training and decision-making to improve the quality of care provided to patients with COVID-19.

\section{INTRODUCTION}

Since the influenza pandemic in 1918, no rapidly spreading disease has caused as much public health concern and profound global impact as the novel coronavirus disease 2019 (COVID-19) pandemic. $^{12}$ COVID-19 is a disease caused by a Betacoronavirus known as severe acute respiratory syndrome coronavirus 2 (SARS-CoV-2). ${ }^{34}$ By $30^{\text {th }}$ June 2020 , there were 10187304 confirmed positive cases and 503872 reported deaths globally and 45524 cases and 350 deaths in Kuwait. ${ }^{5}$ Given the complexity of the situation, the novelty of the disease and its heavy death and economic toll, clinicians have been urged to share and integrate what they know about COVID-19 management. ${ }^{2} 67$ However, the exponential growth of available information has had its drawbacks. Low-quality studies and/or contradicting information have been globally circulated.

Our hospital is one of the biggest hospitals in Kuwait, with a total capacity of 847 beds. It serves more than one million people. ${ }^{8}$ With the emergence of the COVID-19 disease, the Intensive Care Unit (ICU) of the hospital increased its capacity from 40 to 111 beds. The hospital also used many satellite locations outside the main ICU, as Intermediate Care Units or High Dependency Units. The surge in capacity has necessitated the rapid redeployment and recruitment of a large number of healthcare providers. Due to its emergency response, the hospital has become one of the biggest COVID-19 treatment centres in the country.

The expanded ICU faces many challenges, including a large number of redeployed nonintensive care physicians and nurses who have joined work in the ICU, newly recruited intensivists from other hospitals who are not familiar with the local guidelines and critical care physicians and nurses whose cognitive capacities have been overwhelmed by the new stressors, layout changes and drained resources. This situation is exacerbated by the lack of standardised protocols for disease management ${ }^{23}$ and has created an environment where substandard care can flourish, primarily due to variations in practice.

For the past two decades, research has shown that non-compliance with clinical 
practice guidelines is the third leading cause of preventable patient deaths and is responsible for one-third of wasted healthcare expenditure. ${ }^{9}$ Clinical algorithms are considered a highly effective means of handling clinicians' limited cognitive capacity when overwhelmed by a dramatic increase in new clinical information in a short time. ${ }^{9}$ Considering the current struggle to manage the COVID-19 pandemic and warnings of a second wave, ${ }^{10}$ this paper aims to propose a comprehensive improvement project for standardising the care provided to hospitalised patients with COVID-19 using a clinical algorithmbased toolkit. This aim can be achieved by addressing the following secondary objectives:

1. To share the toolkit with others so they can be prepared for the second wave.

2. To invite other institutions to join in the implementation of the comprehensive project.

3. To seek professional feedback as part of our multiple Plan-Do-Study-Act (PDSA) cycles.

Although this paper does not include the implementation of an intervention, it follows the SQUIRE (Standards for Quality Improvement Reporting Excellence) guidelines as a framework for reporting. ${ }^{11}$

\section{METHODS}

\section{Setting}

Our hospital is an 847-bed government hospital in Kuwait, which mainly provides secondary care services and some tertiary services (ie, cardiac surgeries and heart transplants). Though elective admissions and ambulatory care visits have been substantially reduced since the emergence of the COVID-19 crisis, the hospital has not been exclusively dedicated to COVID-19 management. One hundred and seventy-four beds in the wards, plus 70 beds in the ICUs have been allocated to patients with COVID19. Our Anaesthesia, Critical Care and Pain Management Department is one of the best structured and best equipped nationally. Moreover, the hospital has established the first and biggest Extracorporeal Membrane Oxygenation (ECMO) service in the country.

\section{Methodology}

A group of experts in anaesthesia, critical care, public health and healthcare quality worked together and adopted a logical system design approach to produce a toolkit to support the management of patients with COVID-19. The authors conducted a review of the literature in search of a best practice framework for developing clinical algorithms that is reasonably practical without compromising the robustness of the method, as researchers have recommended. ${ }^{12}$ Taking into account these two criteria, we selected Horabin and Lewis' (1980) framework and not Mozena and colleagues' framework (1996) ${ }^{1314}$ We followed a structured seven-step approach in developing the toolkit algorithms and a five-step method in writing them. ${ }^{13}$ Then, we applied Rosenfeld $e t$ $a l$ 's five points to each algorithm. ${ }^{12}$
The seven steps of developing a set of algorithms are: (1) identifying the performance requirement that involves problem solving or decision-making (ie, management of hospitalised patients with COVID-19), (2) defining the problems that need to be addressed (eg, management of oxygen therapy, mechanical ventilation, haemodynamic stabilisation), (3) defining the responsibility to solve the problems (eg, non-intensive care physicians, consultant intensivists), (4) deciding how to use the algorithms (ie, for teaching and guiding care), (5) drafting the first version, (6) testing and revising until reaching graphic appropriateness and (7) testing and revising until learning or performance effectiveness is attained. The first six steps have been completed and are discussed in this paper. The final step will be the subject of future research following full toolkit implementation and evaluation. ${ }^{13}$

The five-step method for writing the algorithms began with: (1) describing the starting point (eg, in online supplemental appendix 1, patients allocation according to modified early warning signs (MEWS)); then (2) describing the outputs or specific solutions (eg, in online supplemental appendix $1, \mathrm{O}_{2}$ nasal cannula up to $6 \mathrm{~L} /$ min, $\mathrm{O}_{2}$ mask (up to $10 \mathrm{~L} / \mathrm{min}$ ) or mechanical ventilation); next, (3) connecting the starting point and the outcome using a case example to develop the decisions; and (4) checking the connecting decisions with experts to conclude whether they are complete or not; finally, (5) repeatedly testing the algorithms until users arrive at consistent decisions. ${ }^{13}$

MS Visio 2016 was used to draw the algorithms, which were manually drafted by the first author. As per Rosenfeld and colleagues' five-point recommendations, graphical representations were limited to three shapes, the logical flow was maintained by reducing clutter, counselling and decision nodes were inserted before any significant patient-preference-dependent decision must be made, each decision node was branched to at least two exit arrows, and finally, arrow crossing was avoided. ${ }^{12}$ MS Excel 2016 was used to create data-collection spreadsheets. MS 365 Forms (online platform) was used to create and host the data-collection online forms.

\section{Ethical considerations}

This paper does not include human subjects as it presents a tool without implementation. No confidential information of any type has been used or disclosed. Hence, ethical approval was not required. It was not appropriate or possible to involve patients or the public in the different phases of this research.

\section{Scientific content}

Considering the short time window available to the team, a critical review type of literature review was conducted. ${ }^{15}$ The team sought to identify the most significant findings by reviewing a number of published articles, guidelines and books; listened to hours of clinical webinars. Moreover, the team were guided by their knowledge and 


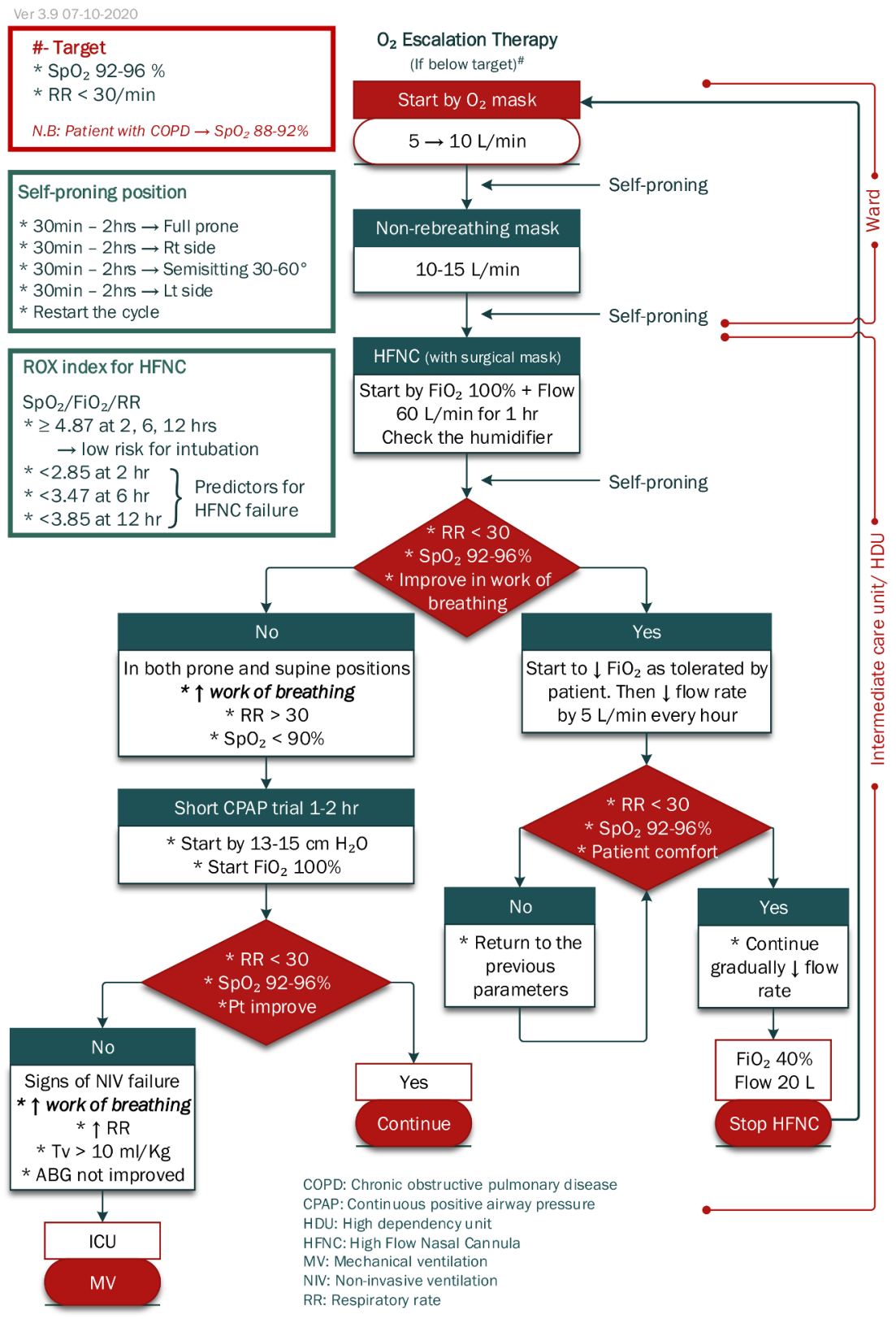

Figure 1 Oxygen escalation therapy. ${ }^{29} 30$

experiences to propose clinical algorithms that address the main issues that have emerged during the management of patients with COVID-19.

\section{RESULTS}

A set of seven clinical algorithms, plus one illustrative layout diagram, has been developed. The algorithm set addresses the following issues: patients allocation according to MEWS, oxygen escalation therapy (figure 1), management of airway during intubation of patients with COVID-19, mechanical ventilation (figure 2), haemodynamic management of patients with COVID-19 (figure 3), immune suppression therapy in patients with COVID-19, anti-coagulant/anti-thrombotic therapy in patients with COVID-19 (figure 4) and weaning of mechanical ventilation (figure 5). Whenever possible, the algorithms include the reference parameters, an abbreviation list and any auxiliary information needed for better understanding and implementation. Online supplemental appendix 1 presents the complete set of algorithms with its references for standalone use and better readability and printing purposes. The set is augmented by documentation forms (online supplemental appendix 2), data-collection online forms and spreadsheets (online supplemental appendix 3) and an indicators' reference sheet (online supplemental appendix 4) to guide implementation and performance measurement.

In accordance with best-practices, the algorithms are composed of three main shapes: 'rounded rectangles to describe a clinical state at entry or completion of a decision sequence, diamond-shaped or hexagonal decision nodes to indicate branch points leading to alternate 
pathways, and rectangles to indicate diagnostic and therapeutic actions' (p. S46) ${ }^{12}$ From the manual sketching of the first algorithm on $24^{\text {th }}$ May 2020 to the approval of the eight-algorithm set (V.3.9) on $7^{\text {th }}$ October 2020, the set underwent many stages of sketching, drafting, reviewing, provisionally approving, adding and deleting and refining before it was finalised. These activities are reflected in the algorithm version number (3.9), where the unit digit (3) indicates the number of major changes introduced to the set (ie, addition or deletion of an algorithm) and the tenth digit (9) indicates the number of minor refinements (eg, addition or deletion of a step, addition of an abbreviation list, graphical rearrangement). Online supplemental appendix 5 presents a table summarising these changes.

To facilitate implementation and monitoring, the set of algorithms has been augmented with supplementary documentation forms (online supplemental appendix 2), data-collection online forms and spreadsheets (online supplemental appendix 3) and an indicators' reference sheet (online supplemental appendix 4). These supplementary tools are designed to be used to document, audit and monitor certain findings in a frequency that reflects compliance with the critical steps of the algorithm and guides decision-making. The indicators' reference sheet

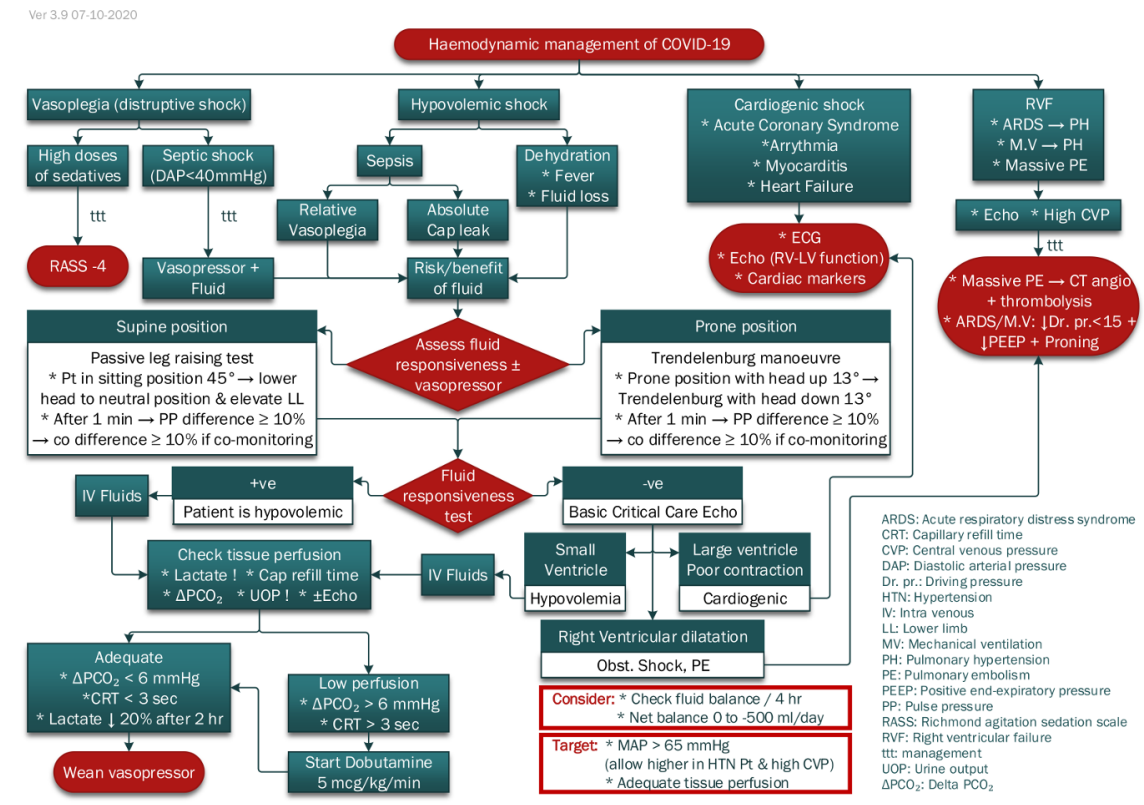

Figure 3 Haemodynamic management of patients with COVID-19. ${ }^{34-36}$ 


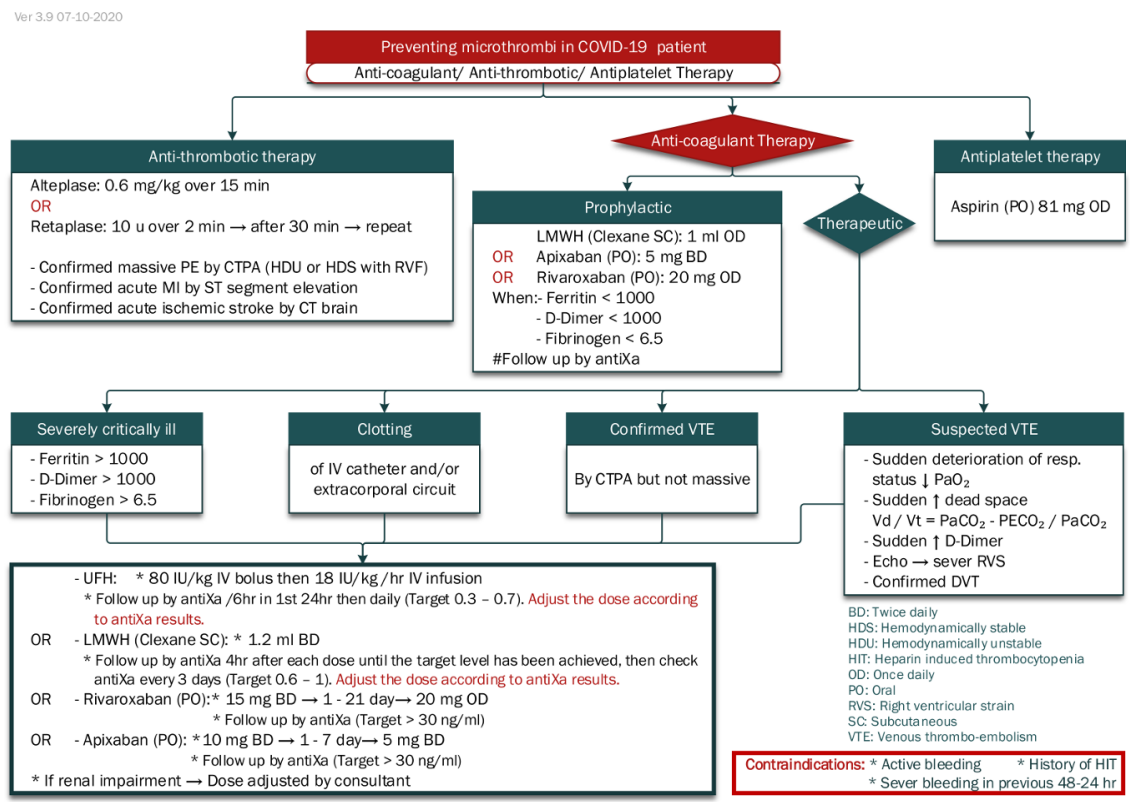

Figure 4 Anti-coagulant/anti-thrombotic therapy in patients with COVID-19. ${ }^{37-39}$

defines which measures are process measures and which are outcome measures.

Feedback was obtained from groups and individuals who work in different organisations, including more than 80 senior and junior ICU physicians, nurses and respiratory therapists. The feedback was intended to explore and evaluate the clinicians' reaction and learning guided by the new Kirkpatrick evaluation model. ${ }^{16}$ Two members of the research team, representing the clinical and quality professions, used verbal feedback, individual and focus group interviews and observation as evaluation tools and methods. These tools and methods have aided in exploring the clinicians' satisfaction and engagement, and the algorithms' content relevance as characteristics which demonstrate the degree of favourable clinicians reaction to the proposed algorithms. ${ }^{16}$ Moreover, an online introduction to the algorithms and on-job training have been offered to practising clinicians. The twomember evaluation team explored, on a very limited scale, the degree of acquiring the intended knowledge, skills, attitudes, confidence and commitment based on the participation in the training events. ${ }^{16}$ The feedback has assisted in selecting the algorithms colour theme, changing the algorithms boxes location to reduce clutter, adding explanatory elements such as the abbreviation lists and testing the feasibility of the use of the algorithms within the work context. The collective feedback showed a positive reaction towards content relevance with less

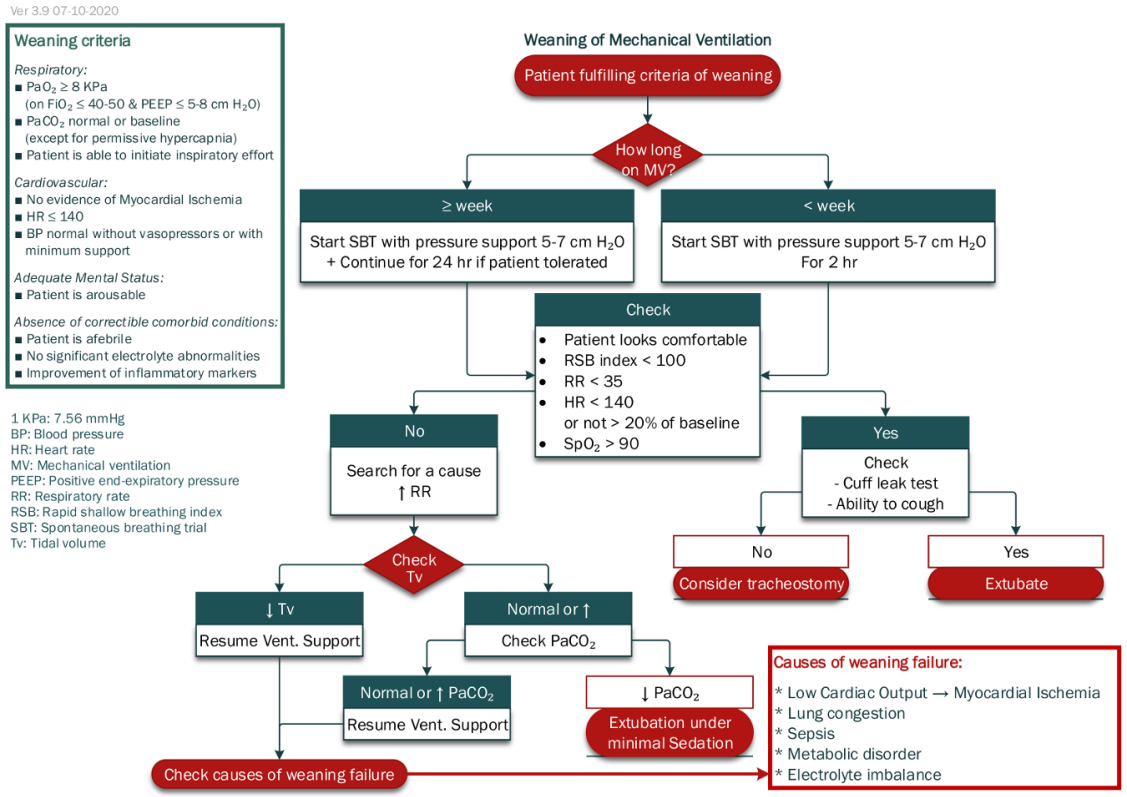

Figure 5 Weaning of mechanical ventilation. ${ }^{33}$ 
positive satisfaction and weaker engagement. However, the clinicians exhibited some 'buy-in' when they had seen that their comments were considered in the subsequent revisions. Regarding the training events, the highest positive feedback was knowledge and skills, while attitudes, confidence and commitment were challenging.

\section{DISCUSSION}

Our hospital is working to improve the quality of care provided to all patients, including patients with COVID19. To this end, the hospital has recently proposed a protocol for safely transporting critically-ill patients with COVID-19, which was published in a high impact peerreviewed journal. ${ }^{17}$ While the first protocol focusses on one problem and introduces a table that fits the nonbranching linear procedure of patient transportation; ${ }^{13}$ this paper proposes a complete toolkit, with a set of clinical algorithms that fits the complex problems and the necessity of making clinical decisions. Although our organisation is a large government secondary-care hospital, the proposed algorithms can be used in other settings that provide inpatient, low-acuity and critical levels of care, including private centres, university hospitals and smaller or larger hospitals.

The research team, which represents a professional panel, relied on its members' judgement to select best-practice clinical guidelines to improve clinicians' decision-making. To obtain the full potential of these guidelines, they were translated into clinical algorithms. ${ }^{9}$ Whether for teaching clinical decision making, or guiding clinical diagnosis and management, a clinical algorithm is defined as a graphical set of sequentially-detailed, explicit steps and instructions, which guide healthcare providers on how to perform a procedure appropriately. ${ }^{18-20}$

"All models are wrong; the practical question is how wrong do they have to be to not be useful". This quote is attributed to the British mathematician and professor of statistics, G. Box. ${ }^{21}$ If this is applied to a more generic entity, a model; it can also be applied to a more specific one, an algorithm. Every patient is unique, and it is impossible to reflect the full complexity of reality and account for every single clinical eventuality. As modelling is intended to reflect the necessary details to understand the modelled subject in some way, ${ }^{22}$ the proposed set of algorithms is intended to be a guiding tool for clinicians during their attempts to diagnose and manage patients with COVID-19.

Since their introduction in the early 1970s, clinical algorithms have had a substantial impact on healthcare delivery and research. ${ }^{19}{ }^{23}$ Recent literature shows that what was theoretically valid in the 1970s and 1980s has been practically demonstrated in the 2010s. A study published in 2017 showed that a referral algorithm, described as a 'simple educational intervention', can effectively reduce the burden of inappropriate referrals and improve service use and cost-efficiency. ${ }^{24}$ Reflecting on hospital practice, this toolkit may reduce the number of patients with COVID-19 who are admitted to limitedcapacity ICUs by following the patient allocation algorithm (figure 1). Moreover, it has been demonstrated that an algorithm-guided, standardised approach to evaluating patients can save resources without sacrificing patient outcomes or diagnostic accuracy. ${ }^{25}$ This is of high importance when looking at current hospital practices of frequently ordering unnecessary follow-up investigations. On the other hand, incidences of late intervention have been reported. Given the fact that most of the interventions in this set of algorithms are supported by clear parameters/findings, which indicate when to initiate, we expect that the interventions will be activated earlier. ${ }^{26}$

In addition, the benefit of using this toolkit is not limited to increased efficiency in resource utilisation or appropriate referrals. Our hospital has recruited and reallocated many non-intensive care clinicians to manage patients with COVID-19. Communication during consultation and handover between new, less-trained clinicians and senior, more-experienced clinicians must be standardised to permit the provision of high-quality, uninterrupted clinical care. The algorithm-based supplementary documentation forms will create a shared mental model where attendance, punctuality, attention, summarisation and provision of anticipatory guidance can be improved. ${ }^{27}$

While the above-mentioned benefits align with highquality care (eg, efficiency, appropriateness and continuity of care), it is worth noting that this initiative also corresponds with the assertions of renowned quality experts; Staines and colleagues during this global pandemic. To avoid the hibernation of quality/patient safety programmes and use the skillset of quality/patient safety experts, Staines and colleagues introduced what can be viewed as a contemporary manifesto for quality activities during a pandemic, such as COVID-19. ${ }^{6}$ The initiative presented in this paper fulfils many of the recommendations that they advocate, such as working to improve care through clinical decision support; gathering, filtering, summarising and briefing experience and evidence; organising just-in-time audits of key relevant practices; strengthening the capacities of the learning system and emphasising the importance of capturing crisis-related improvement opportunities and innovations; and contributing to data analysis, representation and interpretation of variation. ${ }^{6}$

Few, yet important, concerns have been raised regarding calls to develop and use clinical algorithms. Since their early appearance in the literature, clinical algorithms have faced similar objections. The main objections are that algorithms will create unable-to-think robotic clinicians with less individual autonomy, and that they are inapplicable to specific patients. ${ }^{20}{ }^{28}$ In fact, algorithms are frameworks used to facilitate thinking about clinical encounters in a branching logic, which allows individualisation of management and care once the patient is thoroughly examined. ${ }^{14} 1928$

From a behavioural psychology perspective, communicating the results of performance monitoring is a 
cornerstone in changing behaviour. Therefore, an evaluation method must indicate whether or not a behaviour was performed as required. ${ }^{20}$ The algorithm set has been augmented with documentation forms to facilitate implementation by requiring the documentation of certain findings in a frequency that reflects compliance with the algorithm and guides the decision making (online supplemental appendix 2). The documentation forms, in turn, facilitate auditing and performance measurement, as they supply the data needed to monitor critical steps in the spreadsheets (online supplemental appendix 3). This will help to evaluate the effectiveness and timeliness of the care provided, and eventually inform clinicians about how appropriate their decisions were concerning a clinical problem.

Given that one universal and essential characteristic of the current pandemic is coping with a flood of redeployed clinicians and the need for rapid training and learning, a self-paced, free and open-access online training is available to train individual and group clinicians on why and how to use the algorithms and what benefits they may expect. This training, which fits in various staff circumstances and time zones, includes a post-activity feedback assessment and practice exercises to evaluate the usefulness of the training. Moreover, the training entitles participants to claim continuing education credits, which may motivate more clinicians to engage in such educational activity.

The research team members are planning to monitor and report on the current performance in their respective organisations. Benefitting from the easy access to the shared same data-collection online forms, the team can provide a fast performance report to practising clinicians with the added option of benchmarking. After having a foundation of local acceptance, the team intends to seek support from the national clinical bodies and the Quality and Accreditation Directorate in the Ministry of Health, Kuwait, to integrate the indicators list into the current National Indicators Programme. Moreover, the publication of this work as a peer-reviewed article will add some weight to the toolkit and eventually substantiate the research team's call for adopting best practices.

\section{Strengths and limitations}

This paper has several strengths which distinguish it. Excluding papers that describe non-branching linear procedures using a table or a list, there are no previous papers on the management of patients with COVID-19 that fit the standard definition of an algorithm. In addition, the comprehensiveness of the algorithms and the inclusion of the whole management spectrum of patients with COVID-19 are unprecedented. Moreover, this initiative was brought about by critical care physicians, not quality professionals, in response to their awareness of the variation in practice. This will ensure better clinician buy-in to the improvement project.

The scientific contents of the algorithms are up-to-date and universally-accepted best-practices. However, the parameters, drug doses and management thresholds can be revised, customised or modified without destroying the main structure of the algorithms. Furthermore, the algorithms were developed and written following a bestpractice, logical system approach and method. ${ }^{13}$ Finally, the algorithm set, together with the supplementary documentation forms (online supplemental appendix 2), data-collection online forms and spreadsheets (online supplemental appendix 3) and indicators' reference sheet (online supplemental appendix 4) create a unique essential toolkit that is needed in this incomparable challenging situation.

However, some limitations are also present. Although the algorithm set was piloted during its development and writing processes, it was not tested on a larger scale to verify its value in standardising care. The piloting involved few supporting clinicians; which gives a biassed result. Acknowledging the time constrains and the stressing work environment, wider piloting was not possible at that moment. Moreover, the feedback, which has been sought, was verbal and did not follow a structured scheme each time. A qualitative approach to analysing the feedback, if feasible, would have added more insights.

Being an early report proposing a toolkit, the effects of standardisation on clinical outcomes and quality of care have yet to be established. Moreover, the impact of the intervention on behaviour has not been assessed. However, the benefits of using algorithms in changing clinical outcomes and behaviour are supported in the literature. The authors also acknowledge that the shapes used in the algorithms are not standard flowchart elements. Also, more details were needed in some of the shapes. This should be of no concern, as the algorithm set is meant to be used in a clinical context where the shapes of algorithm elements are not rigorously standardised. This decision is also supported in the literature. ${ }^{12}$

\section{Practice implications}

To understand and methodically predict the clinical outcomes of current COVID-19 management practices, clinical processes must first be stabilised and standardised, which is the aim of these algorithms. ${ }^{14}$ The initiative of translating narrative clinical guidelines to morecomprehensible, graphically-represented algorithms may inspire other professional bodies and guideline panels to do the same. Moreover, after demonstrating its effectiveness following implementation, this toolkit will enhance healthcare institutions' readiness and resilience to manage the second COVID-19 wave that looms on the horizon. Furthermore, although the authors' organisation is a large government secondary-care hospital, the proposed algorithms can be used in other settings that provide inpatient, low-acuity and critical levels of care, including private centres, university hospitals and smaller or larger hospitals.

The data-collection online forms and spreadsheets together with the indicators' reference sheet should allow easy measurement of performance and benchmarks 
between different healthcare institutions that decide to use the toolkit. Indicating compliance with clinical guidelines, this measurement is at the core of the science of improvement. ${ }^{914}$ Expecting successful control of the current pandemic, the authors believe that these clinical algorithms could be used as a decision support tool in managing patients with non-COVID ailments. The algorithms for intubation (with some modifications), weaning and haemodynamic management apply to all ICU patients, while mechanical ventilation algorithm applies to any ARDS (acute respiratory distress syndrome) patient.

\section{CONCLUSIONS}

Reality can be chaotic to the extent that one may prefer the abstraction of models or algorithms to make sense of reality. It is true that 'a picture is worth a thousand words'. The considerably large volume of published literature on the topic of COVID-19 pandemic was translated into a user-friendly set of algorithms. Research has demonstrated the many benefits of using decision support tools, such as clinical algorithms. We hope that this toolkit will improve the quality of care provided to patients with COVID-19 by acting as a training and guiding tool. We also hope that the timely sharing of this toolkit will help prepare other institutions to meet the present and future challenges of COVID-19 and similar pandemics. While inviting other institutions to join in the second phase of this research by adopting this toolkit, we advocate that all professional bodies and guideline panels support their clinical guidelines with algorithms.

\section{Author affiliations}

${ }^{1}$ Anaesthesia and Intensive Care Department, Sabah Al Ahmad Urology Centre, Ministry of Health, Sabah, Kuwait

${ }^{2}$ Anaesthesia and Intensive Care Department, Faculty of Medicine, Banha University, Benha, Egypt

${ }^{3}$ Quality and Accreditation Directorate, Ministry of Health, Safat, Kuwait

${ }^{4}$ Anaesthesia, Critical Care and Pain Management Department, Adan Hospital,

Ministry of Health, Hadiya, Kuwait

${ }^{5}$ Critical Care Department, Manchester University NHS Foundation Trust,

Manchester, UK

${ }^{6}$ Public Health Department, Fayoum University Faculty of Medicine, Fayoum, Egypt

Contributors AS reviewed the published literature and drafted the algorithms manually. HA, MS and SA revised and approved the algorithms. HE drew the algorithms using MS Visio, wrote the manuscript and created the data-collection online forms and spreadsheets. IA, MG and LA drafted the documentation forms and $H E$ finalised them. IA and LA drafted the indicators reference sheet and HE and AS finalised it. AS, IA, MG and LA revised the final version of the documentation forms, indicators reference sheet and data-collection online forms and spreadsheets. All authors critically revised the manuscript, gave final approval of the version to be published and are accountable for all aspects of the work. HE is the guarantor of the manuscript.

Funding The authors have not declared a specific grant for this research from any funding agency in the public, commercial or not-for-profit sectors.

Competing interests None declared.

Patient consent for publication Not required.

Provenance and peer review Not commissioned; externally peer reviewed.

Data availability statement All data relevant to the study are included in the article or uploaded as supplementary information.
Supplemental material This content has been supplied by the author(s). It has not been vetted by BMJ Publishing Group Limited (BMJ) and may not have been peer-reviewed. Any opinions or recommendations discussed are solely those of the author(s) and are not endorsed by BMJ. BMJ disclaims all liability and responsibility arising from any reliance placed on the content. Where the content includes any translated material, BMJ does not warrant the accuracy and reliability of the translations (including but not limited to local regulations, clinical guidelines, terminology, drug names and drug dosages), and is not responsible for any error and/or omissions arising from translation and adaptation or otherwise.

Open access This is an open access article distributed in accordance with the Creative Commons Attribution Non Commercial (CC BY-NC 4.0) license, which permits others to distribute, remix, adapt, build upon this work non-commercially, and license their derivative works on different terms, provided the original work is properly cited, appropriate credit is given, any changes made indicated, and the use is non-commercial. See: http://creativecommons.org/licenses/by-nc/4.0/.

ORCID iD

Hossam Elamir http://orcid.org/0000-0002-5573-4023

\section{REFERENCES}

1 Ferguson NM, Laydon D, Nedjati-Gilani G. Impact of nonpharmaceutical interventions (NPIS) to reduce COVID- 19 mortality and healthcare demand, 2020: 20.

2 Galluccio F, Ergonenc T, Garcia Martos A, et al. Treatment algorithm for COVID-19: a multidisciplinary point of view. Clin Rheumatol 2020;39:2077-84.

3 Hasan A, Mehmood N, Fergie J. Coronavirus disease (COVID-19) and pediatric patients: a review of epidemiology, symptomatology, laboratory and imaging results to guide the development of a management algorithm. Cureus 2020;12:e7485.

4 COVID-19 treatment guidelines panel. coronavirus disease 2019 (COVID-19) treatment guidelines, 2020. Available: https://www.covi d19treatmentguidelines.nih.gov [Accessed 22 Jun 2020].

5 World Health Organization. Who coronavirus disease (COVID-19) Dashboard. who coronavirus dis, 2020. Available: https://covid19. who.int [Accessed 1 Jul 2020].

6 Staines A, Amalberti R, Berwick DM, et al. COVID-19: patient safety and quality improvement skills to deploy during the surge. Int $J$ Qual Health Care 2020:1-3.

7 Gattinoni L, Chiumello D, Caironi P, et al. COVID-19 pneumonia: different respiratory treatments for different phenotypes? Intensive Care Med 2020;46:1099-102.

8 The Public Authority for Civil Information. Population STAT. STAT. Servises Syst, 2019. Available: https://www.paci.gov.kw/stat/ SubCategory.aspx?ID=2 [Accessed 2 Jul 2020].

9 Djulbegovic B, Hozo I, Dale W. Transforming clinical practice guidelines and clinical pathways into fast-and-frugal decision trees to improve clinical care strategies. J Eval Clin Pract 2018;24:1247-54.

10 Leung K, Wu JT, Liu D, et al. First-wave COVID-19 transmissibility and severity in China outside Hubei after control measures, and second-wave scenario planning: a modelling impact assessment. Lancet 2020;395:1382-93.

11 Ogrinc G, Davies L, Goodman D, et al. Squire 2.0 (standards for quality improvement reporting excellence): revised publication guidelines from a detailed consensus process. Am J Crit Care 2015;24:466-73.

12 Rosenfeld RM, Shiffman RN, Robertson P. Clinical practice Guideline development manual, third edition: a quality-driven approach for translating evidence into action. Otolaryngol Head Neck Surg 2013;148.

13 Horabin IS, Lewis BN. Algorithms. 2nd ed. Englewood Cliffs, NJ, USA: Educational Technology, 1980.

14 Mozena JP, Emerick CE, Black SC. Clinical Guideline development: an algorithm approach. Gaithersburg, MD, USA: Aspen Publishers Inc, 1996.

15 Grant MJ, Booth A. A typology of reviews: an analysis of 14 review types and associated methodologies. Health Info Libr J 2009;26:91-108.

16 Kirkpatrick DL, Kirkpatrick J. Evaluating training programs: the four levels. 3rd ed. San Francisco, CA, USA: Berrett-Koehler Publishers, 2006.

17 Yousuf B, Sujatha KS, Alfoudri H, et al. Transport of critically ill COVID-19 patients. Intensive Care Med 2020;46:1663-4.

18 Green G, Defoe EC. What is a clinical algorithm? Clin Pediatr 1978;17:457-63. 
19 Komaroff AL. Algorithms and the "art' of medicine. Am J Public Health 1982;72:10-12.

20 Margolis CZ. Uses of clinical algorithms. JAMA 1983;249:627-32

21 GEP B, Draper NR. Empirical model-building and response surfaces. 1st ed. New York, USA: John Wiley \& Sons Inc, 1987.

22 de Ruijter A, Guldenmund F. The bowtie method: a review. Saf Sci 2016;88:211-8.

23 Greenfield S. Clinical algorithms. West J Med 1978;129:230-1.

24 Legg P, Ramoutar D, Shivji F, et al. The construction and implementation of a clinical decision-making algorithm reduces the cost of adult fracture clinic visits by up to $£ 104,800$ per year: a quality improvement study. Annals 2017;99:280-5.

25 Schoel L, Maizlin II, Koppelmann T, et al. Improving imaging strategies in pediatric appendicitis: a quality improvement initiative. $J$ Surg Res 2018;230:131-6.

26 Téoule P, Birgin E, Mertens C, et al. Clinical pathways for oncological gastrectomy: are they a suitable instrument for process standardization to improve process and outcome quality for patients undergoing gastrectomy? A retrospective cohort study. Cancers 2020;12:13.

27 Sochet AA, Ryan KS, Bartlett JL, et al. Standardization of pediatric Interfacility transport handover: measuring the development of a shared mental model. Pediatr Crit Care Med 2018;19:e72-9.

28 Martin GP, Kocman D, Stephens T, et al. Pathways to professionalism? quality improvement, care pathways, and the interplay of standardisation and clinical autonomy. Sociol Health IIIn 2017;39:1314-29.

29 NHS England and NHS Improvement. Clinical guide for the management of critical care for adults with COVID-19 during the coronavirus pandemic. London, UK: NHS England and NHS Improvement, 2020. https://www.england.nhs.uk/coronavirus/ wp-content/uploads/sites/52/2020/03/C0216_Specialty-guide_ AdultCritiCare-and-coronavirus_V2.pdf

30 Long B, Cibrario A, Baker Z. COVID-19: oxygen escalation therapy and noninvasive ventilation, 2020. Available: http://www.emdocs.net/ covid-19-oxygen-escalation-therapy-and-noninvasive-ventilation/ [Accessed 21 Jun 2020].

31 de AMG, Bobek I, Putensen C, et al. Respiratory support, 2020. Available: https://academy.esahq.org/esa/2020/esa-covid-19/ 293216/prof.marcelo.gama.de.abreu.prof.ilona.bobek.prof.christian. putensen.prof.html?f=menu\%3D8\%2Abrowseby\%3D8\%2Asortby\% 3D2\%2Amedia\%3D1\%2Atopic\%3D16792\%2Alabel\%3D19884 [Accessed 21 Jun 2020].

32 Camporota L, Guerin C. How to ventilate in COVID-19, 2020. Available: https://esicm-tv.org/webinar1_live_20-how-to-ventilate-incovid-19.html [Accessed 21 Jun 2020]

33 Marino PL. Mechanical Ventilation. In: Marino's The ICU Book. Philadelphia, PA, USA: Lippincott Williams \& Wilkins, 2014: 487-586.

34 Hajjar L, Teboul J-L, Vincent J-L. Haemodynamic management of COVID-19 septic shock, 2020. Available: https://esicm-tv.org/ webinar11_live_32-haemodynamic-management-of-covid-19-septicshock.html [Accessed 21 Jun 2020].

35 Hasanin A, Mostafa M. Evaluation of fluid responsiveness during COVID-19 pandemic: what are the remaining choices? J Anesth 2020;34:758-64.

36 Vieillard-Baron A, Balik M. 5 minutes echo exam during a pandemic, 2020. Available: https://esicm-tv.org/webinar11_live 32-haemodynamic-management-of-covid-19-septic-shock.html [Accessed 21 Jun 2020].

37 Therapeutics. Boston, MA, USA: : Brigham and Women's Hospital, 2020. Available: https://5eed4dd82e59e4d21bd0003d-covidprotocols.netlify.app/ [Accessed 21 Jun 2020].

38 Barnes GD, Burnett A, Allen A, et al. Thromboembolism and anticoagulant therapy during the COVID-19 pandemic: interim clinical guidance from the anticoagulation forum. J Thromb Thrombolysis 2020;50:72-81.

39 Atallah B, Mallah SI, AIMahmeed W. Anticoagulation in COVID-19. Eur Heart J Cardiovasc Pharmacother 2020;6:260-1. 